\title{
Excess of health care use in general practice and of comorbid chronic conditions in cancer patients compared to controls
}

Lea Jabaaij ${ }^{1}$, Marjan van den Akker ${ }^{2,3}$ and François G Schellevis ${ }^{1,4^{*}}$

\begin{abstract}
Background: The number of cancer patients and the number of patients surviving initial treatments is expected to rise. Traditionally, follow-up monitoring takes place in secondary care. The contribution of general practice is less visible and not clearly defined.

This study aimed to compare healthcare use in general practice of patients with cancer during the follow-up phase compared with patients without cancer. We also examined the influence of comorbid conditions on healthcare utilisation by these patients in general practice.
\end{abstract}

Methods: We compared health care use of $\mathrm{N}=8,703$ cancer patients with an age and gender-matched control group of patients without cancer from the same practice. Data originate from the Netherlands Information Network of General Practice (LINH), a representative network consisting of 92 general practices with 350,000 enlisted patients. Health care utilisation was assessed using data on contacts with general practice, prescription and referral rates recorded between 1/1/2001 and 31/12/2007. The existence of additional comorbid chronic conditions (ICPC coded) was taken into account.

Results: Compared to matched controls, cancer patients had more contacts with their GP-practice (19.5 vs. 11.9, $p<.01$ ), more consultations with the GP (3.5 vs. 2.7, $p<.01)$, more home visits (1.6 vs. $0.4, p<.01)$ and they got more medicines prescribed (18.7 vs. 11.6, $\mathrm{p}<.01)$ during the follow-up phase. Cancer patients more often had a chronic condition than their matched controls ( $52 \%$ vs. $44 \%, \mathrm{p}<.01)$. Having a chronic condition increased health care use for both patients with and without cancer. Cancer patients with a comorbid condition had the highest health care use.

Conclusion: We found that cancer patients in the follow-up phase consulted general practice more often and suffered more often from comorbid chronic conditions, compared to patients without cancer. It is expected that the number of cancer patients will rise in the years to come and that primary health care professionals will be more involved in follow-up care. Care for comorbid chronic conditions, communication between specialists and GPs, and coordination of tasks then need special attention.

Keywords: Neoplasms, Cancer, Primary health care, General practitioner, Follow-up, Comorbidity

\footnotetext{
*Correspondence: f.schellevis@nivel.nl

'NIVEL (Netherlands Institute for Health Services Research), PO Box 1568, Utrecht 3500 BN, The Netherlands

${ }^{4}$ Department of General Practice and Elderly Care Medicine/EMGO Institute for Health and Care Research, VU University Medical Centre, Amsterdam, The Netherlands

Full list of author information is available at the end of the article
} 


\section{Background}

In general, cancer is a disease of the old age. Highest prevalence rates of almost all cancers are found among persons older than 55 years of age. For example, while this age group comprises only $20 \%$ of the population in the United States, over $80 \%$ of the invasive cancers are found in this group [1]. Therefore, with an ageing population (for figures of the Netherlands see [2]), it is expected that the number of cancer patients will increase substantially. Diagnosis, initial treatment of cancer and follow-up care is for the larger part provided by specialists working in secondary care $[3,4]$. With an increasing number of patients with cancer and an increasing number of cancer patients surviving for a longer period of time a reorganization of health care will be necessary. New roles for general practitioners (GPs) and other primary care professionals in cancer care might emerge, for example in follow-up care.

Anticipating these future developments, it is interesting to know what care is currently delivered to cancer patients by GPs. In literature, few studies are found which focus on health care use of cancer survivors in primary care. Roorda et al. [5] reported higher health care utilisation rates in general practice for breast cancer patients during the year after diagnosis compared to the control group. This is in line with the results of a British study [6]: the year after their diagnosis of breast cancer the contact rate of patients with their GP more than doubled compared to the year preceding their diagnosis. Two years after their diagnosis, the contact rate had not yet returned to the baseline level. In a group of longterm survivors of Hodgkin's disease, French researchers found a slight increase in the number of visits to a general practitioner compared to matched control patients [7]. A study that did not match these results concluded that the consultation rates of cancer patients in general practice did not increase when GPs took care for discharged long-term cancer survivors [8]. However, these patients were voluntarily discharged from secondary care and might not be a representative sample of long-term cancer survivors.

We studied health care use in general practice of patients with cancer during the follow-up phase. Did they use more health care in general practice, compared to patients without cancer? Because many cancer patients are older than 65 years, we also focussed on the presence of comorbid chronic conditions and whether these conditions influenced health care use in general practice.

\section{Methods}

\section{Design}

To analyse health care use of cancer patients in general practice we used routinely collected data from the
Netherlands Information Network of General Practice (LINH). We compared the health care use of cancer patients during the follow-up phase with age and gender matched control patients from the same practice in a retrospective cohort study.

\section{General practices}

The Netherlands Information Network of General Practice (LINH) is a representative network consisting of 92 general practices from all over the Netherlands with about 350,000 enlisted patients. In the Netherlands, every inhabitant is listed with a general practitioner. The LINH database holds longitudinal data on GP care, including patient contacts, referrals, prescription medicines, and relevant health problems. Health problems are coded by the GP, using the International Classification of Primary Care (ICPC) [9]. The database is used for health services research and quality of care research. For more information on the network see www.linh.nl.

\section{Patients and controls}

Based on ICPC-codes [see paragraph below] we selected all patients for whom a diagnosis of cancer was recorded between January 1, 2001 and December 31, 2007. This resulted in 8,703 cancer patients, $44 \%$ males and 56\% females for whom health care data were available on a minimum of 30 days during the follow-up phase (see further). The age distribution of the cancer patients is shown in Figure 1.

Cancer patients were matched for age (in five year intervals) and gender with patients without a diagnosis

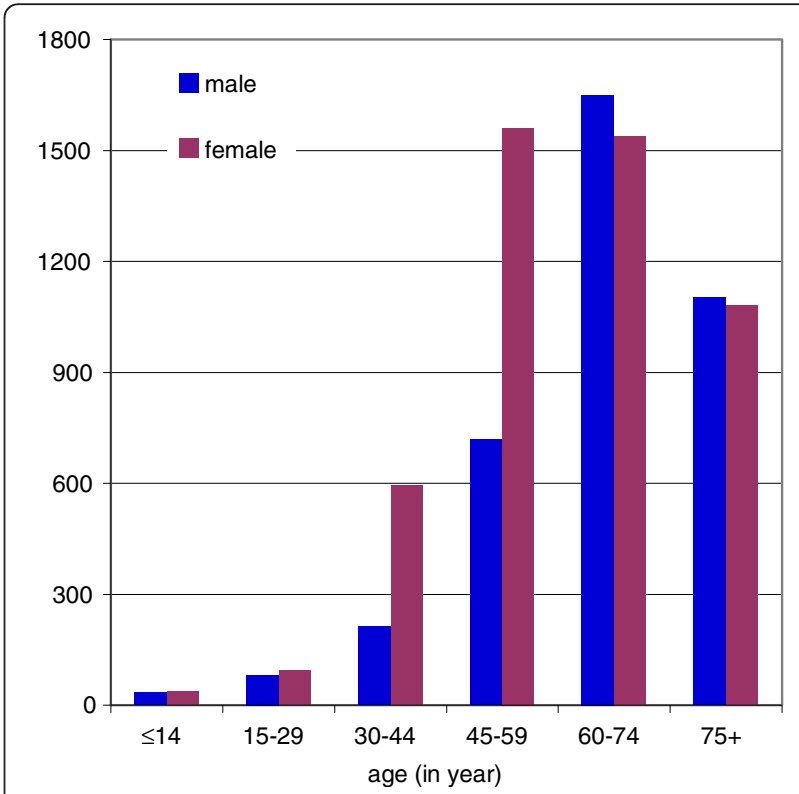

Figure 1 Number of patients with cancer by gender and age group (absolute numbers; males $n=3800$, females $n=4903$ ). 
of cancer, enlisted in the same general practice. We could include 8,672 control patients (data not shown).

\section{Type of cancer}

For $69.2 \%$ of all selected patients with cancer $(\mathrm{N}=8,703)$ one of the following cancer types was recorded: breast cancer (ICPC code X76, 27.7\% of all patients), colon/ rectal cancer (D75, 13.6\% of all patients), prostate cancer (Y77, 13.5\% of all patients), lung/bronchus cancer (R84, 9.3\% of all patients) and cancer of the bladder (U76, 5.1\% of all patients).

For $70.0 \%$ of the female patients with cancer $(\mathrm{N}=4,903)$ one of the following cancer types was recorded: breast cancer (X76, 49.3\% of the women), colon/rectal cancer (D75, 11.8\% of the women), and malignancies of female reproductive organs (X77, 8.9\% of the women).

For $61.2 \%$ of the male patients with cancer $(\mathrm{N}=3,800)$ one of the following cancer types was recorded: prostate cancer (Y77, 30.9\% of the men), colon/rectum cancer (D75, 15.8\% of the men) and lung/bronchus cancer (R84, 14.4\% of the men).

Other cancer types with low numbers of patients included the following ICPC coded cancer types: A79 (malignancy not otherwise specified (NOS)), B72 (Hodgkin's disease/lymphoma), B73 (leukaemia), B74 (malignant neoplasm blood other), D74 (malignant neoplasm stomach), D76 (malignant neoplasm pancreas), D77 (malignant neoplasm digestive system other/NOS), N74 (malignant neoplasm nervous system), R85 (other malignant neoplasm respiratory), S77 (malignant neoplasm of the skin, excluding squamous and basal cell carcinoma), T71 (malignant neoplasm thyroid), U75 (malignant neoplasm of kidney), U77 (malignant neoplasm urinary other), W72 (malignant neoplasm related to pregnancy), X75 (malignant neoplasm cervix uteri), Y78 (malignant neoplasm male genital other).

\section{Follow-up phase and observation period}

We studied use of health care in general practice of cancer patients during the follow-up phase. We defined this phase as starting after the end of the initial treatment and ending before the terminal phase started. Both the initial treatment phase and the terminal phase were excluded, because during these periods patients might have special health care needs that are not representative for the remainder of this period. We set the end of initial treatment to be six months after the first recording of the diagnosis in the electronic medical record (EMR) in the practice and the start of the terminal phase on three months before death or the last registration in the EMR. For reasons of reliability we included only those patients of whom an observation period of at least 30 days was available.
All health care data recorded in the EMR between January 1, 2001 and December 31, 2007 were included in the analyses. Of all patients $78 \%$ was still alive at the end of the observation period, $17 \%$ had died, and $5 \%$ of the patients left the practice because they moved. The length of the observation period differs for every patient, depending on the date of diagnosis. For the most frequently represented types of cancer we found the following median lengths of the observation period: breast cancer (X76) 644 days, colon/rectal cancer (D75) 556 days, prostate cancer (Y77) 598 days, lung/bronchial cancer (R84) 432 days, and cancer of the bladder (U76) 612 days.

\section{Comorbid chronic conditions}

For every patient the presence of comorbid chronic conditions was determined using ICPC coded diagnoses recorded during contacts, prescriptions or referrals. We used the classification for comorbid chronic conditions as described by Knottnerus et al. [10]: sensory conditions (including ear and eye conditions), heart disease, musculoskeletal system, neurological-movement conditions, neurological-pain conditions, psychiatric conditions, respiratory conditions, skin conditions, endocrinological conditions, and urogenital conditions.

\section{Health care use}

The EMR encompasses routinely recorded data for every patient enlisted in the practice, including contacts with the practice, morbidity, referrals to other health care providers and drugs prescribed. The total number of contacts with general practice includes face to face consultations with the GP, home visits, telephone contacts for prescriptions, vaccinations, email contacts, and administrative activities. For all data recorded during the observation period numbers were recalculated to a one year's period.

In the Netherlands the GP functions as the 'gatekeeper' of care, meaning that patients need a referral for specialist health care or for other primary health care workers [11]. The number of referrals can be seen as an indication of the ability of GPs to deal with requests for treatment themselves. We calculated the mean number of new referrals per patient per year.

\section{Analyses}

Cancer patients were compared with age- and gendermatched control patients with regard to the number of contacts with general practice, diagnoses of comorbid conditions, rate of prescribing, and the referral rate in a year.

Furthermore, we studied the influence of having a comorbid chronic condition on health care use. The group of cancer patients without comorbid chronic 
conditions was compared with the matched control group without comorbid chronic conditions while the group of cancer patients with comorbid chronic conditions was compared with the matched control group with comorbid chronic conditions.

We calculated mean figures for the number of contacts with the practice, prescriptions and referrals, and tested for statistical significance of the differences between the two groups using univariate variance analyses (Student's $t$-test). Because of our large sample size, $\mathrm{p}=0.01$ was set as cut-off value for statistical significance.

\section{Results}

\section{Health care use in general practice}

During the period observed, cancer patients used more care in general practice as compared to matched controls without cancer (Table 1). They had more contacts in the general practice in a year, a higher number of face to face consultations with the GP, more home visits, more prescriptions, and more referrals to secondary specialist care.

The higher health care use of cancer patients was found both in males and in females (Table 2). Health care use of cancer patients older than 30 years of age was higher compared to the matched control group. However, cancer patients younger than 30 years of age did not differ from age-matched controls in the number of face to face consultations with the GP, the number of home visits and referrals. But compared to the control group they did have a higher total number of contacts with the general practice, caused by more telephone contacts and/or, email contacts and/or administrative activities in the electronic medical record.

\section{Health care use and comorbid chronic conditions}

The percentage of patients with at least one comorbid chronic condition was higher amongst the group of cancer patients compared to their matched controls (Table 3). This accounts for both men and women, but not for patients younger than 30 years of age.

Table 1 Health care use of cancer patients $(n=8,703)$ compared to matched controls $(n=8,672)$ (mean number and standard error of the mean (SEm) of contacts, prescriptions and referrals per patient in a year)

\begin{tabular}{lcc}
\hline & $\begin{array}{c}\text { cancer patients } \\
\text { (mean and (SEm)) }\end{array}$ & $\begin{array}{c}\text { patients without } \\
\text { cancer } \\
\text { (mean and (SEm)) }\end{array}$ \\
\hline contacts with general practice & $19.5(.2)^{*}$ & $11.9(.1)$ \\
- face to face consultations & $3.5(.05)^{*}$ & $2.7(.04)$ \\
- home visits & $1.6(.06)^{*}$ & $.40(.02)$ \\
prescriptions & $18.7(.2)^{*}$ & $11.6(.2)$ \\
referrals & $0.56(.1)^{*}$ & $0.42(.1)$ \\
\hline
\end{tabular}

* difference between cancer patients and patients without cancer: $\mathrm{p}<0.01$.
Compared to the matched control group, GPs recorded heart disease, psychological, respiratory, skin and urogenital problems more often for cancer patients (Table 4). Endocrinological problems, amongst which diabetes, were the most frequent problems but they are not more frequently recorded in cancer patients than in the matched control patients.

We split both groups (patients with and without cancer) in two according to the presence of comorbid chronic conditions (Table 5). Having cancer is related to significantly more health care use in general practice, irrespective of having a comorbid chronic condition. Patients with both cancer and a comorbid chronic condition have the highest use of care in general practice.

\section{Discussion}

\section{Use of care in general practice}

We found that during the follow-up phase cancer patients have double the use of health care services in general practice compared to controls. This included face to face contacts with GPs, home visits, prescribed medication and referrals to secondary specialist's care. In the period after the end of initial treatment and before the start of the terminal phase, patients with cancer have more contacts with the general practice, amongst which more face to face consultations with the GP, more home visits, more prescriptions and they are more often referred to secondary care. They have more often one or more comorbid chronic conditions, amongst which heart, psychological, respiratory, skin and urogenital problems. Having a comorbid chronic condition further increases health care use in general practice.

In the literature, the few studies describing primary health care use of cancer patients report conflicting results $[5-8,12,13]$. One of the reasons is that health care systems and accessibility of secondary care differs between countries. Our study gives evidence that in the Dutch gatekeeper system, general practice has a substantial role in delivering care to cancer patients. This is in line with Roorda et al. [5] who reported more face to face contacts of breast cancer patients with GPs, more drug prescriptions and more referrals to secondary care during the year after the diagnosis compared to the year preceding the diagnosis.

\section{Comorbidity}

Patients with both cancer and comorbid chronic conditions have the highest health care use in general practice. Comparable results were reported by Kurtz et al. [14] in the United States who found that use of primary care physicians' services depended substantially on comorbid conditions. Koroukian et al. [15] also reported that the complexity of health care demand increases when patients have cancer plus 
Table 2 Health care use of cancer patients by gender and age group ( $n=8,703$ ) (mean number of contacts, prescriptions and referrals per patient in a year)

\begin{tabular}{|c|c|c|c|c|c|c|c|c|}
\hline & \multicolumn{2}{|c|}{ gender } & \multicolumn{6}{|c|}{ age group (year) } \\
\hline & male & female & $\leq 14$ & $15-29$ & $30-44$ & 45-59 & $60-74$ & $75+$ \\
\hline contacts with general practice & $20.0^{*}$ & $19.1^{*}$ & $10.3^{*}$ & $8.9^{*}$ & $12.5^{*}$ & $16.3^{*}$ & $20.4^{*}$ & $25.4^{*}$ \\
\hline - face to face consultations & $3.6^{*}$ & $3.4^{*}$ & 1.8 & 1.7 & $2.7^{*}$ & $3.2^{*}$ & $4.0^{*}$ & $3.5^{*}$ \\
\hline - home visits & $1.8^{*}$ & $1.5^{*}$ & 0.8 & 0.1 & $0.4^{*}$ & $0.9^{*}$ & $1.5^{*}$ & $3.1^{*}$ \\
\hline prescriptions & $19.5^{*}$ & $18.0^{*}$ & $5.1^{*}$ & $5.5^{*}$ & $8.5^{*}$ & $13.6^{*}$ & $19.7^{*}$ & $27.8^{*}$ \\
\hline referrals & $0.50^{*}$ & $0.60^{*}$ & 0.27 & 0.26 & $0.52^{*}$ & $0.48^{*}$ & $0.60^{*}$ & $0.62^{*}$ \\
\hline
\end{tabular}

* health care use of cancer patients is significantly higher compared to the health care use of the gender- and age-matched control group without cancer (figures of the control group not shown; $\mathrm{p}<0.01)$.

comorbid chronic conditions plus physical disability and/or geriatric syndromes. De Bock et al. [16] reported an increased prescription of psychotropic medication for female breast cancer patients on endocrine therapy. Anti-depressants were only prescribed during a short period, but anxiolytics, hypnotics and sedatives were prescribed for a much longer period. These data indicate increased psychological distress due to breast cancer diagnosis and/or treatment in women on endocrine therapy.

Several authors report that cancer survivors do not seem to receive the same quality of care for their comorbid conditions compared to the general population [12]. Examples are diabetes care [17], cardiopulmonary rehabilitation programs [18] or outpatient management of antithrombotic treatment $[19,20]$. Health care professionals seem to be more focused on cancer-related care compared to non-cancer related health care needs. Given the increase in the number of older patients who have more comorbid chronic conditions, this is a point of attention.

Table 3 Percentage of cancer patients $(n=8,703)$ and patients without cancer $(n=8,672)$ with at least one comorbid chronic condition

\begin{tabular}{lcc}
\hline & cancer patients (\%) & $\begin{array}{c}\text { patients without } \\
\text { cancer (\%) }\end{array}$ \\
\hline - all & $51.9^{*}$ & 44.5 \\
- male & $52.0^{*}$ & 43.9 \\
- female & $51.8^{*}$ & 44.9 \\
Age group & & \\
- - 14 year & 22.5 & 12.5 \\
- 15-29 year & 19.3 & 17.0 \\
- 30-44 year & $31.4^{*}$ & 24.2 \\
- 45-59 year & $42.1^{*}$ & 34.0 \\
- 60-74 year & $56.3^{*}$ & 50.2 \\
- 75+ year & $66.6^{*}$ & 58.1 \\
\hline
\end{tabular}

* difference between cancer patients and patients without cancer: $p<0.01$.
Follow-up cancer care by GPs

We found that, in the Netherlands, health care use by cancer patients in general practice is quite substantial. It is expected that the role of GPs will increase further in the future. Cancer follow-up care is recognized internationally as a pressing health care issue. The number of patients is increasing, causing more strain on specialized in-hospital care. The benefit of follow-up in secondary care is questioned [21]. A more prominent role of GPs in follow-up care might come of help.

What do patients think of such a role for the GP? Patients often developed strong relationships with the specialist and staff members like nurses in the hospital during their treatment $[22,23]$. They hold the opinion that their GP is not sufficiently informed about their disease and treatment, and they did not want to bother their GPs with complaints [22]. However, Norwegian researchers found that both GPs and cancer patients valued the role of the GP in shared follow-up care as long as the specialist is easily accessible [24]. In several

Table 4 Percentage of cancer patients $(n=8,703)$ and patients without cancer $(n=8,672)$ with a comorbid chronic condition

\begin{tabular}{lcc}
\hline & cancer patients (\%) & $\begin{array}{c}\text { patients without } \\
\text { cancer (\%) }\end{array}$ \\
\hline Clusters of conditions: & 1 \\
- sensory (including ear and eye) & 1 & 16 \\
- heart disease & $19^{*}$ & 11 \\
- musculoskeletal system & 12 & 1 \\
- neurological-movement & 2 & 2 \\
- neurological-pain & 2 & 7 \\
- psychological & $10^{*}$ & 8 \\
- respiratory & $10^{*}$ & 5 \\
- skin & $8^{*}$ & 19 \\
- endocrinological & 21 & 4 \\
- urogenital & $6^{*}$ & 5 \\
* difference between cancer patients and patients without cancer: $\mathrm{p}<0.01$.
\end{tabular}


Table 5 Health care use of cancer patients and patients without cancer by the presence of a comorbid chronic condition (mean number of contacts, prescriptions and referrals per patient in a year)

\begin{tabular}{lcccc}
\hline & \multicolumn{2}{c}{ No chronic condition } & & \multicolumn{2}{c}{ One or more chronic conditions } \\
\cline { 2 - 5 } & $\begin{array}{c}\text { cancer patients } \\
(\mathbf{n}=\mathbf{4 , 1 9 0 )}\end{array}$ & $\begin{array}{c}\text { patients without } \\
\text { cancer }(\mathbf{n}=\mathbf{4 , 8 1 6 )}\end{array}$ & $\begin{array}{c}\text { cancer patients } \\
(\mathbf{n}=\mathbf{4 , 5 1 3 )}\end{array}$ & $\begin{array}{c}\text { patients without } \\
\text { cancer }(\mathbf{n}=\mathbf{3 , 8 5 6 )}\end{array}$ \\
\hline contacts per year & $14.4^{*}$ & 7.1 & $24.3^{*}$ & 18.0 \\
- face to face consultations per year & $2.6^{*}$ & 1.8 & $4.3^{*}$ & 4.0 \\
- home visits per year & $1.3^{*}$ & 0.2 & $2.0^{*}$ & 0.7 \\
prescriptions per year & $12.0^{*}$ & 5.6 & $24.9^{*}$ & 19.1 \\
referrals per year & $0.4^{*}$ & 0.2 & $0.7^{*}$ & 0.6 \\
\hline
\end{tabular}

* difference between cancer patients and patients without cancer : $p<0.01$.

countries such initiatives arise, in which GPs join secondary care professionals in delivering follow-up care, so-called 'shared care'. These initiatives can have different formats: from a scheduled consultation with the GP following the initial treatment [25] to a 'shared care' program in which specialists communicate extensively with GPs after discharge of the patient from the hospital and patients are stimulated to contact their GP in case of questions and problems [26]. To facilitate follow-up care for both GPs and patients a web-based survivor care plan might be used, including data on diagnosis, treatment and potential risks as well as recommendations for follow-up. In a recent study, such a web-based survivor care plan was positively evaluated by both patients and GPs [27].

Communication between specialist and GP is reported regularly as a major problem for the GP in delivering adequate care $[28,29]$. Standard information supplied by the specialist is often insufficient or too late. The coordination of patient care and communication between GPs and cancer specialists was found to improve when GPs are able to consult the electronic medical record of the specialist $[30,31]$. Furthermore, the development of guidelines, describing tasks and coordination in follow-up care for both specialists and GPs is of utmost importance [21].

\section{Limitations of the study}

Because most patients are diagnosed with cancer in secondary care, the exact date of diagnosis is not always recorded appropriately in the EMR of the GP, neither is the date of the end (or start) of treatment. Therefore, we had to estimate the start of the follow-up phase: six months after the first recording of the diagnosis of cancer in the EMR. The date of the end of the observation period due to death or other reasons is registered accurately in the EMR, so we could exclude the terminal phase. The majority of cancer patients studied was still alive at the end of the study period. These facts combined, mean that the length of the follow-up phase studied differed for the cancer patients depending on time of inclusion, date of death or end of the study period.

\section{Conclusion}

We found that cancer patients in the follow-up phase had higher health care utilisation in general practice compared to patients without cancer. It is expected that primary health care professionals will be involved even more in follow-up care for cancer patients in the future. When shifting the balance of follow-up care to general practice, attention is needed for the fact that many cancer patients have comorbid chronic conditions that need special attention. Consideration is then needed for coordination of tasks and communication between specialists and GPs.

\section{Competing interests}

The authors declared that they have no competing interests.

\section{Author's contribution}

MvdA and FS designed the study and applied for funding. $L J$ contributed to the final design of the study, carried out the analyses and took the lead in writing the manuscript. FS and MvdA commented on draft versions of the manuscript. All authors read and approved the final version.

\section{Acknowledgment}

The study was funded by the Dutch Cancer Society and performed by The Working Group on 'Primary Care for Cancer Patients during Follow-up' of the Signalling Committee Cancer of the Dutch Cancer Society.

\section{Author details}

${ }^{1}$ NIVEL (Netherlands Institute for Health Services Research), PO Box 1568, Utrecht 3500 BN, The Netherlands. ${ }^{2}$ Caphri: School for Public Health and Primary Care, Department of General Practice, Maastricht University, Maastricht, The Netherlands. ${ }^{3}$ Department of General Practice, Katholieke Universiteit Leuven, Leuven, Belgium. ${ }^{4}$ Department of General Practice and Elderly Care Medicine/EMGO Institute for Health and Care Research, VU University Medical Centre, Amsterdam, The Netherlands.

Received: 18 January 2012 Accepted: 2 June 2012

Published: 19 June 2012

\section{References}

1. Thun MJ, Wingo PA: Cancer Epidemiology. In Cancer Medicine. 5th edition. Edited by Bast RC, Kufe DW, Pollock RE, Weichselbaum RR, Holland E, Frei JF. Hamilton: BC Decker; 2000.

2. Statistics Netherlands: Key figures of the population forecasts 2010-2060 in the Netherlands. http://bit.ly/KOZPyg.

3. Grunfeld E, Fitzpatrick R, Mant D, Yudkin P, Adewuyi-Dalton R, Stewart J, Cole D, Vessey M: Comparison of breast cancer patient satisfaction with follow-up in primary care versus specialist care: results from a randomized controlled trial. Br J Gen Pract 1999, 49:705-710. 
4. Summerton N: General practitioners and cancer. BMJ 2000, 320:1090-1091.

5. Roorda $\mathrm{C}$, de Bock $\mathrm{GH}$, van der Veen WJ, Lindeman A, Jansen $L$, van der Meer K: Role of the general practitioner during the active breast cancer treatment phase: an analysis of health care use. Support Care Cancer 2012, 20:705-714.

6. Macleod U, Ross S, Twelves C, George WD, Gillis C, Watt GCM: Primary and secondary care management of women with early breast cancer from affluent and deprived areas: retrospective review of hospital and general practice records. BMJ 2000, 320:1442

7. Joly F, Henry-Amar M, Arveux P, Reman O, Tanguy A, Peny AM, Lebailly P, Lesec'h J, Vie B, Genot JY, Busson A, Troussard X, Leporrier M: Late psychosocial sequelae in Hodgkin's disease survivors: a French population-based case-control study. J Clin Onc 1996, 14:2444-2453.

8. Chait I, Glynne-Jones R, Thomas S: A pilot study exploring the effect of discharging cancer survivors from hospital follow-up on the workload of general practitioners. Br J Gen Pract 1998, 48:1241-1243.

9. Wood M, Lamberts H: International Classification of Primary Care: prepared for the World Organisation of National Colleges, Academies and Academic Associations of General Practitioners/Family Physicians (WONCA) by the ICPC Working Party. Oxford: Oxford University Press; 1987.

10. Knottnerus JA, Metsemakers J, Hoppener P, Limonard C: Chronic illness in the community and the concept of social prevalence. Fam Pract 1992, 9:15-21.

11. Cardol M, de Bakker DH, Westert GP: The activities of general practitioners: are they still gatekeepers? In Morbidity, Performance and Quality in Primary Care. Dutch General Practice on Stage. Edited by Westert GP, Jabaaij L, Schellevis FG. Oxford: Radcliffe Publishing; 2006:107-114.

12. Khan NF, Ward A, Watson E, Austoker J, Rose PW: Long-term survivors of adult cancers and uptake of primary health services: a systematic review. Eur J Cancer 2008, 44:195-204.

13. Khan NF, Ward A, Watson E, Rose PW: Consulting and prescribing behaviour for anxiety and depression in long-term survivors of cancer in the UK. Eur J Cancer 2010, 46:3339-3344.

14. Kurtz ME, Kurtz JC, Given CW, Given BA: Utilization of services among elderly cancer patients - relationship to age, symptoms, physical functioning, comorbidity, and survival status. Ethn Dis 2005, 15:S17-S22.

15. Koroukian SM, Murray P, Madigan E: Comorbidity, disability, and geriatric syndromes in elderly cancer patients receiving home health care. J Clin Oncol 2006, 24:2304-2310.

16. de Bock GH, Musters RF, Bos HJ, Schröder CP, Mourits MJ, de Jong-van den Berg LT: Psychotropic medication during endocrine treatment for breast cancer. Support Care Cancer 2012, 20:1533-1540

17. Liu W, Vyas A, Escalante C, Weiser MA, Wang J, Geraci JM: Results of general internal medicine consultations for diabetes mellitus in 283 cancer patients. Am J Med Sci 2007, 333:276-279.

18. Nazarian J: Cardiopulmonary rehabilitation after treatment for lung cancer. Curr Treat Options Oncol 2004, 5:75-82.

19. Ageno W, Grimwood R, Limbiati S, Dentali F, Steidl L, Wells PS Home-treatment of deep vein thrombosis in patients with cancer. Haematologica 2005, 90:220-224.

20. Siragusa S, Arcara C, Malato A, Anastasio R, Valerio MR, Fulfaro F, Lo CL, Grimaudo S, Bajardi G, Abbadessa V, Gebbia N: Home therapy for deep vein thrombosis and pulmonary embolism in cancer patients. Ann Oncol 2005, 16(Suppl 4):iv136-iv139.

21. Grunfeld E: Looking beyond survival: how are we looking at survivorship? J Clin Oncol 2006, 24:5166-5169.

22. Aanom BIRG, Pfeiffer PER: Why are some patients in treatment for advanced cancer reluctant to consult their GP? Scand J Prim Health Care 2009, 27:58-62.

23. Barnes EA, Fan G, Harris K, Doyle M, Librach LS, Chow E, Barbera L, Tsao M, Lam K, Danjoux C: Involvement of family physicians in the care of cancer patients seen in the palliative Rapid Response Radiotherapy Program. J Clin Oncol 2007, 25:5758-5762.

24. Anvik T, Holtedahl KA, Mikalsen H: "When patients have cancer, they stop seeing me" - the role of the general practitioner in early follow-up of patients with cancer - a qualitative study. BMC Fam Pract 2006, 7:19.

25. Holtedahl K, Norum J, Anvik T, Richardsen E: Do cancer patients benefit from short-term contact with a general practitioner following cancer treatment? A randomised, controlled study. Support Care Cancer 2005, 13:949-956.
26. Nielsen JD, Palshof T, Mainz J, Jensen AB, Olesen F: Randomised controlled trial of a shared care programme for newly referred cancer patients: bridging the gap between general practice and hospital. Qual Saf Health Care 2003, 12:263-272

27. Blaauwbroek R, Barf HA, Groenier KH, Kremer LC, van der Meer K, Tissing WJE, Postma A: Family doctor-driven follow-up for adult childhood cancer survivors supported by a web-based survivor care plan. $J$ Cancer Surviv 2012, 6:163-171.

28. Dworkind M, Towers A, Murnaghan D, Guibert R, Iverson D: Communication between family physicians and oncologists: qualitative results of an exploratory study. Cancer Prev Control 1999, 3:137-144.

29. Johansson B, Berglund G, Hoffman K, Glimelius B, Sjoden PO: The role of the general practitioner in cancer care and the effect of an extended information routine. Scand J Prim Health Care 2000, 18:143-148.

30. Jiwa M, Saunders CM, Thompson SC, Rosenwax LK, Sargant S, Khong EL, Halkett GK, Sutherland G, Ee HC, Packer TL, Merriman G, Arnet HR: Timely cancer diagnosis and management as a chronic condition: opportunities for primary care. Med J Aust 2008, 189:78-82.

31. Sisler J, McCormack-Speak P: Bridging the gap between primary care and the cancer system: the UPCON Network of CancerCare Manitoba. Can Fam Physician 2009, 55:273-278.

doi:10.1186/1471-2296-13-60

Cite this article as: Jabaaij et al.: Excess of health care use in general practice and of comorbid chronic conditions in cancer patients compared to controls. BMC Family Practice 2012 13:60

\section{Submit your next manuscript to BioMed Central and take full advantage of:}

- Convenient online submission

- Thorough peer review

- No space constraints or color figure charges

- Immediate publication on acceptance

- Inclusion in PubMed, CAS, Scopus and Google Scholar

- Research which is freely available for redistribution 